\title{
Influence of sex after elective thoracic endovascular aortic repair
}

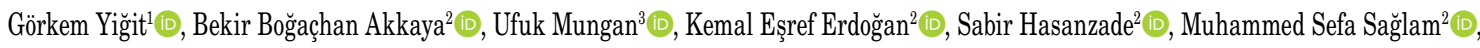 \\ Ertekin Utku Ünal ${ }^{4}$ D, Hakkı Zafer İşcan² ${ }^{\mathbb{D}}$ \\ ${ }^{1}$ Department of Cardiovascular Surgery, Yozgat City Hospital, Yozgat, Turkey \\ ${ }^{2}$ Department of Cardiovascular Surgery, Ankara City Hospital, Ankara, Turkey \\ ${ }^{3}$ Department of Cardiovascular Surgery, Lokman Hekim Akay Hospital, Ankara, Turkey \\ ${ }^{4}$ Department of Cardiovascular Surgery, Hitit University Faculty of Medicine, Çorum, Turkey
}

\begin{abstract}
Objectives: This study aims to evaluate the early and mid-term outcomes of sex influence after elective thoracic endovascular aortic repair (TEVAR).

Patients and methods: A total of 69 patients (46 males, 23 females; mean age: $61.2 \pm 16.0$ years; range, 42 to 86 years) who underwent an elective TEVAR between January 2019 and January 2021 were retrospectively analyzed. The patients were divided into two groups according to sex. All procedures were performed by the same endovascular team. Mainly Medtronic's Valiant ${ }^{\circledR}$ and Lifetech's Ankura ${ }^{\circledR}$ thoracic endografts were used. Technical success, early (30-day) morbidity and mortality, mid-term mortality, and secondary intervention rates were evaluated.
\end{abstract}

Results: Early mortality was $4.35 \%$ for both sex ( $\mathrm{p}=0.975$ ). In the early postoperative period, no complications requiring any reintervention were encountered. Eighteen patients experienced intentional left subclavian artery coverage. Prophylactic carotid-subclavian bypass was performed in two males and one female before the TEVAR procedure. Delayed left subclavian artery revascularization was performed in one male patient due to left arm ischemia. There was no other neurovascular complication. In the follow-up period (13 \pm 6.9 months), reintervention was performed in one female and two male patients for type 1 endoleak and one Petticoat procedure two months after the first TEVAR. There was only one late mortality due to retrograde type A dissection at the postoperative third month.

Conclusion: Our findings suggest that TEVAR in female sex is safe and effective with successful early morbidity and mortality results. The sex difference does not affect the early and mid-term outcomes of elective TEVAR.

Keywords: Outcome, sex, TEVAR, thoracic aortic aneurysm, type B dissection.

For thoracic aortic aneurysms (TAAs) and type-B aortic dissections (TBADs), thoracic endovascular aortic aneurysm repair (TEVAR) is the first-line treatment, owing to its less invasive nature and successful early morbidity and mortality results. ${ }^{[1]}$ Open conventional surgery still carries higher mortality and morbidity with regard to thoracotomy, extensive surgical resection, aortic cross-clamp, hypothermia, ischemia, blood loss. ${ }^{[2]}$ As patient population is overaged, even masterpiece operations may be complicated by coexisting cardiopulmonary comorbidities. The TEVAR may potentially offer significant reductions in the mortality and morbidity.

Sex differences in outcomes after vascular surgery exist and have been well studied. ${ }^{[3-13]}$ There are differences between sexes at every stage of the disease, from epidemiology to pathophysiology and from morbidity to mortality. ${ }^{[1,8,11]}$ Females usually present with smaller aneurysms along with greater growth rates and rupture risk. In spite of these facts,

Received: May 31, 2021 Accepted: June 26, 2021 Published online: July 26, 2021

Correspondence: Görkem Yiğit, MD. Park Vadi Evleri Sitesi, Bilal Şahin Mahallesi, Ylldırım Bayezit Cad., No: 4, 66100 Yozgat, Türkiye. e-mail: drgorkemyigit@gmail.com 
the current guidelines indicate earlier intervention for females. ${ }^{[1,11]}$ The rational approach to aneurysm management in females must balance the hazards of repair with the probability of mortality from aneurysm rupture. For abdominal aortic aneurysms, female sex has worse outcomes after both open and endovascular repair. ${ }^{[5,6]}$

Different from abdominal aortic cases, for thoracic aortic pathologies, the ratio of men-to-women is between $1: 1$ and 3:1..$^{[1,3,8-11]}$ Women have a smaller normal diameter for aortas, smaller caliber access vessels and more complex aortic pathologies complicating not only open surgery, but endovascular procedures as well. As the patient population is not sufficient for women in cross-sectional or single-center studies, meta-analyses or reviews take place for comment. ${ }^{[7,11-13]}$

Considering all these reasons, there is currently little information concerning the outcomes of female patients following TEVAR. One recent large-scale, retrospective study of TEVAR using the National Surgical Quality Improvement Program data showed female sex to be associated with the increased 30-day mortality. ${ }^{[7]}$ However, after adjusting for intraoperative variables, they suggested that the mortality difference might be, in part, explained by varying aortoiliac and femoral arterial disease burden between sexes. In the present study, we aimed to investigate sex differences on mortality and secondary interventions in our TEVAR experience and to present our mid-term follow-up results.

\section{PATIENTS AND METHODS}

This retrospective study was conducted at Ankara State Hospital, Department of Cardiovascular Surgery between January 2019 and January 2021. A total of 69 patients (46 males, 23 females; mean age: $61.2 \pm 16.0$ years; range, 42 to 86 years) who underwent isolated elective TEVAR were included. The patients were divided into two groups according to sex and demographics and pre-, peri-, and postoperative findings were recorded. Urgent or hybrid procedures, complicated acute type $\mathrm{B}$ aortic dissections, aortic transections, procedures such as simultaneous TEVAR and endovascular aortic repair (EVAR) were excluded. All procedures were performed by the same endovascular surgical team. A written informed consent was obtained from each patient. The study protocol was approved by the Ankara State Hospital Ethics Committee (No: E1-20-603). The study was conducted in accordance with the principles of the Declaration of Helsinki.
Data including age, preoperative comorbidities, electrocardiogram (ECG), transthoracic echocardiography (TTE), and tomographic findings such as TAA diameter were evaluated. Perioperatively, amount of contrast agent, fluoroscopy time, cerebrospinal fluid (CSF) drainage, length of intensive care unit (ICU) stay and length of hospital stay (LOS) were noted.

Computed tomography angiography (CTA) was the first-line preoperative imaging modality to determine individual aortic anatomy and obtain measurements for strategy and sizing. Almost all procedures were performed under general anesthesia, except for one female patient with penetrating aortic ulcer who refused to experience general anesthesia and, instead, local anesthesia with limited sedation was performed to allow holding breath while taking angiogram shots. The ECG and TTE were performed for all patients. Coronary angiography was used for only symptomatic patients.

A follow-up imaging with CTA was routinely obtained for all patients at the first three months according to the patient's status and complication risks after hospital discharge and annually, thereafter.

\section{Operative technique}

All TEVAR procedures were performed in the hybrid operating room. A radial artery catheterization was inserted to monitor systemic blood pressure. Anticoagulation was ensured during the operation by heparin bolus (5,000 IU) at the beginning of the femoral catheterization, with additional heparin as needed to maintain an activating clotting time $(\mathrm{ACT})$ of $>250 \mathrm{sec}$. The CSF drainage was selectively performed and the drainage set was routinely inserted by an anesthesiologist before the procedure and heparin to minimize the risk of intrathecal or epidural bleeding with perioperative anticoagulation. The CSF was monitored for 24 to $72 \mathrm{~h}$ after the procedure. The CSF pressure was kept at a level of 8 to $10 \mathrm{cmH}_{2} \mathrm{O}$ and drainage was performed up to 48 to $72 \mathrm{~h}$, if necessary. Balloon angioplasty was not applied to the patients in the presence of type $\mathrm{B}$ dissection.

For providing adequate landing zone, the left subclavian artery (LSA) or celiac artery may be sacrificed. Prior to coverage of the celiac artery, the anatomy and collaterals of the mesenteric vascular beds were carefully evaluated using preoperative CTA and digital subtraction angiography (DSA) intraoperatively. For LSA, similar approach was taken as preoperative studies for supra-aortic vessels, 
Table 1. Demographic and clinical characteristics of male and female patients

\begin{tabular}{|c|c|c|c|c|c|c|c|c|c|c|c|c|c|}
\hline \multirow[b]{2}{*}{ Comorbidity } & \multicolumn{4}{|c|}{ Female (n=23) } & \multicolumn{4}{|c|}{ Male $(\mathrm{n}=46)$} & \multicolumn{4}{|c|}{ Total $(\mathrm{n}=69)$} & \multirow[b]{2}{*}{$p$} \\
\hline & $\mathrm{n}$ & $\%$ & Mean $\pm S D$ & Min-Max & $\mathrm{n}$ & $\%$ & Mean \pm SD & Min-Max & $\mathrm{n}$ & $\%$ & Mean \pm SD & Min-Max & \\
\hline Age (year) & & & $59.8 \pm 16.8$ & $43-83$ & & & $62.6 \pm 15.1$ & $42-86$ & & & $61.2 \pm 16.0$ & $42-86$ & 0.387 \\
\hline Diabetes mellitus & 6 & 26.1 & & & 7 & 15.2 & & & 13 & 18.8 & & & 0.111 \\
\hline Hypertension & 14 & 60.9 & & & 32 & 69.5 & & & 46 & 66.6 & & & 0.530 \\
\hline Hyperlipidemia & 8 & 34.8 & & & 14 & 30.4 & & & 22 & 31.9 & & & 0.284 \\
\hline Chronic obstructive pulmonary disease & 9 & 39.1 & & & 20 & 43.5 & & & 29 & 42 & & & 0.862 \\
\hline Coronary artery disease & 2 & 8.7 & & & 15 & 32.6 & & & 17 & 24.6 & & & 0.095 \\
\hline Coronary artery bypass grafting & 0 & 0 & & & 5 & 10.9 & & & 5 & 7.2 & & & 0.157 \\
\hline Chronic renal failure & 2 & 8.7 & & & 8 & 17.4 & & & 10 & 14.5 & & & 0.441 \\
\hline Cerebrovascular event & 2 & 8.7 & & & 3 & 6.5 & & & 5 & 7.2 & & & 0.565 \\
\hline Peripheral arterial disease & 0 & 0 & & & 5 & 10.9 & & & 5 & 7.2 & & & 0.586 \\
\hline Symptomatic & 12 & 52.2 & & & 19 & 41.3 & & & 31 & 44.9 & & & 0.776 \\
\hline
\end{tabular}

TEVAR: Thoracic endovascular aortic repair.

vertebral dominancy, cerebral blood supply from CTA and colored Doppler ultrasonography (CDUS) and, in the absence of contraindications including anatomical variations and/or stenosis, we covered the LSA with concern of the aortic extension without prophylactic or simultaneous revascularization. Delayed revascularization was performed, if necessary. While deployment, arterial blood pressure was always kept around 70 to $80 \mathrm{mmHg}$. After stent graft deployment, angiographic control for endoleaks was routinely performed as a completion angiogram. An endovascular balloon catheter (Reliant ${ }^{\circledR}$ balloon, Medtronic Inc., Santa Rosa, CA, USA or Tri-Lobe ${ }^{\circledR}$ balloon, W.L., Gore \& Associates, Inc., Newark, DE, USA) was not liberally used to all landing or connection zones. The endografts used in this study was mainly the Medtronic's Valiant ${ }^{\circledR}$ (Medtronic Inc., Minneapolis, MN, USA) and LifeTech's Ankura ${ }^{\circledR}$ (LifeTech Scientific, Shenzhen, Guangzhou, China) thoracic endografts.

The primary outcome measures of the study were technical success, early (30-day) morbidity and mortality. Late mortality and secondary interventions after TEVAR were the secondary endpoints at the mid-term follow-up period. Early mortality was defined as any postoperative death within 30 days or death occurring during the hospital stay.

\section{Statistical analysis}

Statistical analysis was performed using the SPSS for Windows version 15.0 software (SPSS Inc., Chicago, IL, USA). Descriptive data were expressed in mean \pm standard deviation (SD), median (interquartile range $[\mathrm{IQR}]$ ) or number and frequency. Continuous variables were analyzed using the independent samples t-test or Mann-Whitney U-test, while categorical variables were analyzed using the chi-square test or Fisher's exact test. A $p$ value of $<0.05$ was considered statistically significant.

\section{RESULTS}

Demographic data of both sexes are shown in Table 1. Although the male group was older than the female group, it was not statistically significant $(\mathrm{p}=0.387)$. Also, there was no statistically significant difference in the baseline demographic and clinical characteristics of the patients. Chronic obstructive pulmonary disease $(p=0.862)$, chronic renal failure $(\mathrm{CRF})(\mathrm{p}=0.441)$, and coronary artery disease (CAD) $(p=0.095)$ were more common in males, although it did not reach statistical significance. Besides, peripheral arterial disease (PAD) and prior coronary artery bypass graft $(\mathrm{CABG})$ were only seen in the male group, probably due to the advanced age with a high rate of atherosclerosis in this group.

Etiological classification of aortic pathologies based on sex is shown in Table 2. For both sexes, atherosclerotic fusiform TAA was the most seen etiological and anatomical pathology. Both females and males had similar etiological structures.

Table 2. Etiological classification of aortic pathologies regarding to sex

\begin{tabular}{lccccccc}
\hline & \multicolumn{2}{c}{ Female } & & \multicolumn{3}{c}{ Male } & \\
\cline { 2 - 3 } & $\mathrm{n}$ & $\%$ & & $\mathrm{n}$ & $\%$ & & $p$ \\
\hline Type-B aortic dissection & 8 & 34.7 & & 15 & 32.6 & \\
Fusiform aneurysm & 9 & 39.1 & & 22 & 47.8 & 0.748 \\
Saccular aneurysm & 6 & 26.1 & & 9 & 19.6 & \\
\hline
\end{tabular}


Table 3. Operative data

\begin{tabular}{lcccccc}
\hline & \multicolumn{2}{c}{ Female } & & \multicolumn{2}{c}{ Male } & \\
\cline { 2 - 3 } & Mean \pm SD & Min-Max & & Mean \pm SD & Min-Max & $p$ \\
\hline Fluoroscopy time & $11 \pm 5.6$ & $6-25$ & & $10.9 \pm 6.5$ & $4-32$ & 0.685 \\
Contrast (mL) & $66.8 \pm 19.5$ & $40-70$ & & $71.0 \pm 26.4$ & $40-110$ & 0.970 \\
ICU time (h) & $16.6 \pm 14.8$ & $4-72$ & & $14.2 \pm 13.0$ & $1-160$ & 0.193 \\
LOS (day) & $4.4 \pm 4.0$ & $1-20$ & & $5.8 \pm 5.5$ & $1-22$ & 0.343 \\
\hline ICU: Intensive care unit: LOS: Length of hospital stay & & & &
\end{tabular}

Table 4. Postoperative data

\begin{tabular}{lcccccc}
\hline & \multicolumn{2}{c}{ Female $(\mathrm{n}=23)$} & & \multicolumn{2}{c}{ Male $(\mathrm{n}=46)$} & \\
\cline { 2 - 3 } & $\mathrm{n}$ & $\%$ & & $\mathrm{n}$ & $\%$ & \\
\hline Proximal landing zones & 4 & 17.4 & & 20 & 43.5 & \\
$\quad$ Zone 2 & 3 & 13.05 & & 3 & 6.5 & \\
$\quad$ Zone 3 & 13 & 56.5 & & 20 & 43.5 & \\
$\quad$ Zone 4 & 3 & 13.05 & & 3 & 6.5 & \\
$\quad$ Zone 5 & & & & & 0.273 \\
LSA revascularization & 1 & 4.3 & & 2 & 3.2 & \\
$\quad$ Prophylactic & 0 & 0 & & 1 & 1.6 & \\
$\quad$ Delayed & 0 & 0 & & 6 & 13 & \\
$\quad$ SMFSG & 2 & 8.7 & & 13 & 28.2 & 0.063 \\
CSF drainage & 4 & 17.4 & & 14 & 30.4 & 0.245 \\
LSA closure & 0 & 0 & & 1 & 1.6 & 0.476 \\
Celiac closure & 1 & 4.35 & & 4 & 4.35 & 0.975 \\
Early mortality & & &
\end{tabular}

LSA: Left subclavian artery; SMFSG: Surgeon Modified Fenestrated Stent Graft; CSF: Cerebrospinal fluid.

Early mortality was identical for both sexes (4.35\%) $(p=0.975)$. In the early period, no complications requiring any reintervention were encountered. In the mean follow-up of $13 \pm 6.9$ months, reintervention was performed in one female and two male patients for type 1 endoleaks and one Petticoat procedure to one male patient two months after the first TEVAR procedure. There was only one mortality in the follow-up period due to retrograde type A dissection at the postoperative third month who had TEVAR procedure for type $\mathrm{B}$ aortic dissection in the subacute phase.

Operative data of the patients are shown in Table 3. The mean aneurysm diameter was larger in males compared to females; however, there was no statistically significant difference $(59.8 \pm 15.2 \mathrm{~mm}$ vs. $55.7 \pm 9.3 \mathrm{~mm}$, respectively) $(\mathrm{p}=0.297)$. Procedural duration was longer and amount of contrast material that was used during the procedure was higher in the female group which could be due to anatomical obstacles, although it did not reach statistical significance ( $\mathrm{p}=0.685$ and $\mathrm{p}=0.970$, respectively). Also, there was no statistically significant difference in the mean length of ICU stay $(16.6 \pm 14.8 \mathrm{~h}$ for females vs. $14.2 \pm 13 \mathrm{~h}$ for males) $(\mathrm{p}=0.193)$ and mean LOS between the groups $(4.4 \pm 4$ days for females vs. $5.8 \pm 5.5$ days for males; $\mathrm{p}=0.343)$. There was one celiac closure, 18 LSA closure three of whom had prophylactic carotid-subclavian bypass (CSB), one had delayed CSB due to left arm ischemia. The patients were discharged without any complication. After July 2020, back-table fenestration was initiated in our clinic and, in anatomically suitable patients, the surgeon-modified fenestrated stent graft (SMFSG) technique was performed for zone 2 landing to provide patency of LSA. ${ }^{[14,15]}$ Six fenestrated stent grafts were successfully oriented in that period and they were all patent in the early follow-up. The CSF drainage was selectively used and 15 patients (21.74\%) experienced CSF drainage. Proximal landing zones, CSF drainage, LSA and celiac closures, and their distribution between the groups are summarized in Table 4.

\section{DISCUSSION}

Our TEVAR experience showed satisfactory early and mid-term morbidity and mortality outcomes for both sexes. The early mortality rate was $4.35 \%$ for both sexes $(p=0.975)$. After surviving TEVAR procedure, the mid-term follow-up period was uneventful and satisfactory. Czerny et al..$^{[5]}$ conducted a retrospective review of their TEVAR experience in 286 patients and observed no mortality difference based on sexes. A sub-study of the evaluation of the Medtronic Vascular Talent Thoracic Stent Graft system for the treatment of TAAs (VALOR trial) examined outcomes according to sexes in 195 patients. ${ }^{[9]}$ They found worse early outcomes for females; however, once recovered from the initial TEVAR, women had satisfactory long-term outcomes. They concluded the sex difference on early outcomes solely be related to peri-procedural-related complications. The anatomical difficulties and peri-procedural complications due to smaller diameters and aortic tortuosity seems to be responsible for these results. Another suggestion for better results may be the earlier repair in females, as it is recommended in the current guidelines. Low-profile devices for broadening the treatment spectrum is also an important issue.

The previous sex-specific studies comparing males and females in TEVAR has shown that female patients are associated with numerically higher early mortality and outcomes. ${ }^{[5,7,9,12,13]}$ Indeed, the inconsistent results obtained in these 
studies can be attributed to a number of factors including the population size, etiological structures, symptomatology of the patients at presentation, evolving technology, practices, and the use of different stents and their sizing. The lower early mortality is possible with suitable anatomy, team experience, and device improvements over time. ${ }^{[13,16]}$ Complicated aortic or vessel anatomy, worse baseline health and more symptomatic aneurysms may be possible reasons. In our study, symptomatic patients were numerically higher in female group than the male group $(52.2 \%$ vs. $41.3 \%$, respectively); however, there were no significant differences in the baseline demographics. Male patients had more $\mathrm{CAD}, \mathrm{CABG}, \mathrm{CRF}$, and PAD, although it did not reach statistical significance, but showed a higher burden of cardiovascular atherosclerotic disease in males. These results suggest that TEVAR is safe and effective for both sexes with regard to early mortality and morbidity. After surviving the procedure, the early follow-up period was uneventful in this study and, therefore, the key issue should be anatomical specialties or peri-procedural complications and older-generation devices regarding profiles.

A proper proximallanding zone requires coverage of the LSA in 26 to $40 \%$ of patients undergoing TEVAR. ${ }^{[18-20]}$ In 2009, the Society for Vascular Surgery (SVS) Guidelines on LSA revascularization were published; Nevertheless, controversy continues about this debate. ${ }^{[18]}$ Some surgeons perform revascularization routinely, some selectively, and some only perform LSA revascularization, if symptoms occur after TEVAR. ${ }^{[18-20]}$ The reason for prophylactic revascularization is to reduce neurovascular complications. ${ }^{[18-20]}$ In our clinic, we used to perform selective LSA revascularization based on the individual anatomic features of each patient. In this study, prophylactic CSB was performed in only three patients. The LSA closure was applied to 18 patients (26.1\%) (4 females, 17.4\% and 14 males, 30.4\%). Delayed LSA revascularization was performed in one male patient due to left arm ischemia. The patients were discharged without any complication. We decided to act independently for each patient according to the extension of the aortic pathology, the length of the aorta covered, condition of the supra-aortic arch vessels, the condition of the abdominal aorta and iliac arteries. To provide patency of the LSA endovascularly while landing at zone 2 , since July 2020, the SMFSG technique and back-table fenestration were the treatment of choice and performed in anatomically suitable patients. ${ }^{[14,15]} \mathrm{Six}$ fenestrated stent grafts were successfully oriented up to January 2021 and they were all patent in the early follow-up period.

The exact mechanism of paraplegia and spinal ischemia after TEVAR has not been clearly elucidated, yet. After TEVAR, the foremost neurological complications are paraplegia and stroke. ${ }^{[21-24]}$ The incidence of spinal cord ischemia following TEVAR varies considerably across studies between 0 and 10\%. ${ }^{[21-24]}$ After TEVAR, the presence of adequate collateral circulation can prevent cord ischemia. The CSF drainage have been the commonly used adjunct in reducing cord ischemia in open thoracoabdominal aneurysm repair. ${ }^{[21-24]} \mathrm{We}$ performed CSF drainage during and up to 48 to $72 \mathrm{~h}$ following TEVAR. We selectively applied CSF drainage in 15 patients (21.7\%) (2 females, $8.7 \%$ and 13 males, 28.2\%, respectively). In addition, we did not encounter any cerebrovascular events in the perioperative period in both sex groups.

The longer LOS for females was also evident in previous studies. ${ }^{[5-7,11,12]}$ This condition may be related to the increased rate of complications, psychosocial factors such as anxiety or availability of home care. In our study, the ICU period was slightly longer in females; however, the LOS was slightly longer in male patients with no statistically significant difference.

Limited number of studies are available on sexspecific reintervention rates after TEVAR. More importantly, some studies have reported higher reintervention rates in males. ${ }^{[25,26]}$ Endoleak is the most common indication for secondary interventions. ${ }^{[25,26]}$ In the present study, reintervention was performed in one female and two male patients for type 1 endoleaks in the follow-up period. The reason why these results could not be compared with other series may be explained by the relatively low number of patients.

The main limitations of this study are the limited female patient population as other cross-sectional, single-center studies and the lack of a comparison with open surgery patients for the same period. The decision to repair an aortic aneurysm weighs the rupture risk, life expectancy and morbidity and mortality risk associated with repair.

In conclusion, TEVAR in female patients seems to be safe and effective with successful early morbidity and mortality results without any sex difference. Further studies with larger patient cohorts would 
enable us to determine the most appropriate threshold for female patients and to comment on the interaction between sex and TEVAR outcomes to improve overall management.

\section{Declaration of conflicting interests}

The authors declared no conflicts of interest with respect to the authorship and/or publication of this article.

\section{Funding}

The authors received no financial support for the research and/or authorship of this article.

\section{REFERENCES}

1. Upchurch GR Jr, Escobar GA, Azizzadeh A, Beck AW, Conrad MF, Matsumura JS, et al. Society for Vascular Surgery clinical practice guidelines of thoracic endovascular aortic repair for descending thoracic aortic aneurysms. J Vasc Surg 2021;73(1S):55S-83S.

2. Rigberg DA, McGory ML, Zingmond DS, Maggard MA, Agustin M, Lawrence PF, et al. Thirty-day mortality statistics underestimate the risk of repair of thoracoabdominal aortic aneurysms: A statewide experience. J Vasc Surg 2006;43:217-22.

3. Tumer NB, Askin G, Akkaya BB, Civelek I, Unal EU, Iscan HZ. Outcomes after EVAR in females are similar to males. BMC Cardiovasc Disord 2021;21:301.

4. Yavas S, Mavioglu L, Kocabeyoglu S, Iscan HZ, Ulus AT, Bayazit $\mathrm{M}$, et al. Is female gender really a risk factor for carotid endarterectomy? Ann Vasc Surg 2010;24:775-85.

5. Czerny M, Hoebartner M, Sodeck G, Funovics M, Juraszek A, Dziodzio T, et al. The influence of gender on mortality in patients after thoracic endovascular aortic repair. Eur J Cardiothorac Surg 2011;40:e1-5.

6. Ouriel K, Greenberg RK, Clair DG, O'hara PJ, Srivastava SD, Lyden SP, et al. Endovascular aneurysm repair: Gender-specific results. J Vasc Surg 2003;38:93-8.

7. Arnaoutakis GJ, Schneider EB, Arnaoutakis DJ, Black JH 3rd, Lum YW, Perler BA, et al. Influence of gender on outcomes after thoracic endovascular aneurysm repair. J Vasc Surg 2014;59:45-51.

8. Lepidi S. Should we look differently at aortic aneurysm in women? Eur J Vasc Endovasc Surg 2018;56:441.

9. Jackson BM, Woo EY, Bavaria JE, Fairman RM. Gender analysis of the pivotal results of the Medtronic Talent Thoracic Stent Graft System (VALOR) trial. J Vasc Surg 2011;54:358-63.

10. Lo RC, Lu B, Fokkema MT, Conrad M, Patel VI, Fillinger $\mathrm{M}$, et al. Relative importance of aneurysm diameter and body size for predicting abdominal aortic aneurysm rupture in men and women. J Vasc Surg 2014;59:1209-16.

11. Wanhainen A, Verzini F, Van Herzeele I, Allaire E, Bown M, Cohnert T, et al. Editor's choice - European Society for Vascular Surgery (ESVS) 2019 clinical practice guidelines on the management of abdominal aorto-iliac artery aneurysms. Eur J Vasc Endovasc Surg 2019;57:8-93.
12. Deery SE, Shean KE, Wang GJ, Black JH 3rd, Upchurch GR Jr, Giles KA, et al. Female sex independently predicts mortality after thoracic endovascular aortic repair for intact descending thoracic aortic aneurysms. J Vasc Surg 2017;66:2-8.

13. Ulug P, Powell JT, Warschkow R, von Allmen RS. Editor's choice - Sex specific differences in the management of descending thoracic aortic aneurysms: Systematic review with meta-analysis. Eur J Vasc Endovasc Surg 2019;58:503-11.

14. İş̧ $\mathrm{HZ}$, Ünal EU. Surgeon-modified fenestrated stent graft deployment in type B aortic dissection. Turk Gogus Kalp Dama 2021;29:285-9.

15. Ünal EU, İşcan HZ, Mavioğlu HL, Özatik MA. Zone 2 landing at different aortic pathologies: Surgeon-modified fenestrated stent graft. Turk J Vasc Surg 2021 [Article in Press]

16. Witheford M, Chong DST, Martin-Gonzalez T, Van Calster K, Davis M, Prent A, et al. Women undergoing endovascular thoracoabdominal aortic aneurysm repair differ significantly from their male counterparts preoperatively and postoperatively. J Vasc Surg 2020;71:748-57.

17. O’Donnell TFX, Verhagen HJ, Pratesi G, Pratesi C, Teijink JAW, Vermassen FEG, et al. Female sex is associated with comparable 5-year outcomes after contemporary endovascular aneurysm repair despite more challenging anatomy. J Vasc Surg 2020;71:1179-89.

18 Matsumura JS, Lee WA, Mitchell RS, Farber MA, Murad MH, Lumsden AB, et al. The Society for Vascular Surgery Practice Guidelines: Management of the left subclavian artery with thoracic endovascular aortic repair. J Vasc Surg 2009;50:1155-8.

19. Zamor KC, Eskandari MK, Rodriguez HE, Ho KJ, Morasch MD, Hoel AW. Outcomes of thoracic endovascular aortic repair and subclavian revascularization techniques. J Am Coll Surg 2015;221:93-100.

20 Delafontaine JL, Hu B, Tan TW, Tang GL, Starnes BW, Virk C, et al. Outcome comparison of TEVAR with and without left subclavian artery revascularization from analysis of nationwide inpatient sample database. Ann Vasc Surg 2019;58:174-9.

21. Estrera AL, Miller CC 3rd, Chen EP, Meada R, Torres $\mathrm{RH}$, Porat EE, et al. Descending thoracic aortic aneurysm repair: 12-year experience using distal aortic perfusion and cerebrospinal fluid drainage. Ann Thorac Surg 2005;80:1290-6.

22. Drinkwater SL, Goebells A, Haydar A, Bourke P, Brown L, Hamady M, et al. The incidence of spinal cord ischaemia following thoracic and thoracoabdominal aortic endovascular intervention. Eur J Vasc Endovasc Surg 2010;40:729-35.

23. Griepp RB, Griepp EB. Spinal cord perfusion and protection during descending thoracic and thoracoabdominal aortic surgery: The collateral network concept. Ann Thorac Surg 2007;83:S865-9.

24. Coselli JS, LeMaire SA, Köksoy C, Schmittling ZC, Curling PE. Cerebrospinal fluid drainage reduces paraplegia after thoracoabdominal aortic aneurysm repair: 
Results of a randomized clinical trial. J Vasc Surg 2002;35:631-9.

25. Matsumoto AH, Angle JF, Secic M, Carlson GA, Fisher L, Fairman RM. Secondary procedures following thoracic aortic stent grafting in the first 3 years of the VALOR test and VALOR II trials. J Vasc Interv Radiol 2014;25:685-92.e5.

26. Leurs LJ, Harris PL, Buth J; EUROSTAR Collaborators. Secondary interventions after elective endovascular repair of degenerative thoracic aortic aneurysms: Results of the European collaborators registry (EUROSTAR). J Vasc Interv Radiol 2007;18:491-5. 